Acta Technologica Agriculturae 4

Nitra, Slovaca Universitas Agriculturae Nitriae, 2017, pp. 104-109

\title{
APPLICATION OF SIX SIGMA USING DMAIC METHODOLOGY IN THE PROCESS OF PRODUCT QUALITY CONTROL IN METALLURGICAL OPERATION
}

\author{
Lenka GIRMANOVÁ*, Marek ŠOLC, Juraj KLIMENT, Adriana DIVOKOVÁ, Vojtech MIKLOŠ \\ Technical University of Košice, Košice, Slovak Republic
}

The Six Sigma DMAIC can be considered a guide for problem solving and product or process improvement. The majority of companies start to implement Six Sigma using the DMAIC methodology. The paper deals with application of Six Sigma using the DMAIC methodology in the process of product quality control. The case study is oriented on the field of metallurgical operations. The goal of the Six Sigma project was to ensure the required metallurgic product quality and to avoid an increase in internal costs associated with poor product quality. In this case study, a variety of tools and techniques like flow chart, histogram, Pareto diagram, analysis of FMEA (Failure Mode and Effect Analysis) data, cause and effect diagram, logical analysis was used. The Sigma level has improved by approximately $13 \%$. The achieved improvements have helped to reduce the quantity of defective products and the processing costs (technology for re-adjusting). Benefits resulting from the DMAIC implementation can be divided into three levels: the qualitative, economic and safety level.

Keywords: DMAIC methodology; Six Sigma; product quality control; root cause; quality improvement

As competition grows stronger, the providing of quality products and services has become a competitive advantage and a need to ensure survival in this era of globalisation (Jirasukprasert et al., 2014). There are several different definitions of the quality concept and many different opinions on what should be encompassed in the concept of product quality. The quality of a product is its ability to satisfy and preferably exceed the needs and expectations of customers. In the more recent history of quality development, the quality improvement programme Six Sigma has been proved effective (Thakore et al., 2014). The Sigma $(\sigma)$ variable represents the parameter that measures the variability of a statistical distribution, that is, its standard deviation (Garrido-Vega et al., 2016). In quality control terms, Sigma $(\sigma)$ has been traditionally used for measuring the variation in a process or its output (Omachonu and Ross, 2004). In the Six Sigma terminology, the "Sigma level" is denoted as a company's performance (Pyzdek and Keller, 2010). The Six Sigma aim is focused on the reduction of defect frequency in products and processes to a frequency of less than 3.4 defects per million opportunities (DPMO, equivalent to a quality level of $99.9997 \%$ ) (Garrido-Vega et al., 2016; Patil et al., 2015). The DPMO concept is not just a slogan, but much more an established way to measure how successfully Six Sigma objectives are implemented (Thakore et al., 2014). Brue and Howes (2005) mention that Six Sigma is also a management philosophy and strategy, as well as a problem-solving and improvement methodology that can be applied to every type of process in order to eliminate the root cause of defects. Through optimal parameters of processes, it is possible to decrease the costs of the firm and to economise business (Teplická et al., 2015). In particular cases, some authors argue that the main benefits that an organisation can gain from applying Six Sigma are: cost reduction, cycle time improvements, defect elimination, an increase in customer satisfaction and a significant rise in profits (Jirasukprasert et al., 2014). All in all, Six Sigma is aimed at elimination of defects in processes and human related defects (Gijo and Rao, 2005; Gijo and Scaria, 2013). Therefore, especially industrial companies must use proper equipment, and employees must have sufficient knowledge and skills and appropriate technology (Ingaldi et al., 2016). The Six Sigma philosophy is based on the fact that products and services must be delivered with high quality in relation to economy and customer satisfaction.

One of the Six Sigma's distinctive approaches to process and quality improvement is the DMAIC (Define, Measure, Analyse, Improve and Control) method (Garza-Reyes et al., 2010). This method is similar to the Deming's process improvement model PDCA (plan-do-check-act) (Rusinko and Hovanec, 2011). Sigma and DMAIC can help manufacturing organisations to achieve quality improvements in their processes and thus contribute to their search for process excellence (Jirasukprasert et al., 2014).

Six Sigma's rationale during the project corresponds to the five phases of the DMAIC basic tool and is geared towards transforming the growing problem into a project, as well as towards the most accurate expression in a project document. On the basis of measured output quantities that should correspond to Critical Quality Criteria as much as possible, the real problem becomes a statistical problem in the Measure phase. The main causes of the problem are statistically generated and verified in the Analyse phase. Suggested solutions are processed, tested and transformed 
into a real application in the Improve phase. In the Control phase, metrics are continually assessed and improved for quality assurance (Pica, 2011).

The main goal of this paper was to describe the application of Six Sigma using the DMAIC methodology in the process of product quality control in the metallurgical operation. The objective of the project was to improve the quality of the product by eliminating or reducing the occurrence of the defects causing the poor product quality in order to achieve the quality improvement and meet the internal customer expectations. The project was directed to the area of control and delivery of the final product, which is an annealed coil delivered to the following production division.

\section{Material and methods}

The operation, in which the improvement project was implemented, is a part of the production division of a metallurgical plant with a long tradition. Coils, sheets and strips from the production division are used in the automobile, engineering and construction industries, as well as in the production of white kitchen appliances.

In the metallurgical operation, cold-rolled steel coils are heat-treated by recrystallisation annealing in annealing furnaces. After recrystallisation annealing, the annealed coil must have the required mechanical and physical properties, as well as the glossy and clean surface of the strip.

In operation, there was a problem with product quality. The physical properties required by the annealing process met the customer requirements, but annealed coils were often degraded by surface, shape and other defects. Therefore, product processing had to be partially or totally suspended.

As up to $40 \%$ of the deliveries to following production division (internal customer) did not meet the requirements, a project to improve the quality of annealed coils using the
DMAIC methodology wasimplemented.The implementation of the project corresponds to the five phases of DMAIC. In these phases, various tools and techniques like flow chart, histogram, Pareto chart, FMEA (Failure Mode and Effect Analysis), Ishikawa diagram, logical analysis were used. These methods offer many tools for improving the process of performance according to DMAIC (Prístavka et al., 2016). Table 1 shows the summary of the project phases, outputs from each phase and tools and techniques used during the project implementation.

\section{Results and discussion}

\section{Phase D - Define}

Steel coils are supplied for processing in the form of rolled sheet metal strips. The output product is an annealed coil. Annealed coils are delivered for further processing to the following production division (internal customer).

If the annealed coil does not meet the requirements of an internal customer, it is returned to previous processing stage for re-adjustment. Such a step requires resources. This fact is reflected in the increasing cost of operation and represents the losses in the form of product weight decrease associated with removal of the problematic part. If the defect is not discovered in time, the internal customer must shut the production down for several hours.

Problem description: Up to $40 \%$ of all deliveries to the internal customer did not meet the required parameters: $30 \%$ of products are returned due to non-conformity, $8 \%$ are delayed deliveries, and remaining $2 \%$ represent other errors.

Goal definition: The goal of the project was to reduce the number of failed deliveries by $50 \%$ (to less than $20 \%$ ) and to reduce the processing costs by $50 \%$.

Project implementation time was scheduled for 4-5 months.

Table 1 Summary of the project phases

\begin{tabular}{|c|c|c|c|}
\hline Phase & Description & Outputs & Tools and techniques \\
\hline Define & $\begin{array}{l}\text { - problem description and identification of } \\
\text { defects that cause non-conformity } \\
\text { - definition of current performance } \\
\text { - definition of objective goals } \\
\text { - training of coaching team }\end{array}$ & $\begin{array}{l}\text { - timetable } \\
\text { - Six Sigma committee } \\
\text { - project charters (goals) } \\
\text { - flow charts } \\
\text { - Sigma metrics: initial estimate }\end{array}$ & $\begin{array}{l}\text { - brainstorming } \\
\text { - Sipoc diagram }\end{array}$ \\
\hline Measure & $\begin{array}{l}\text { - data gathering regarding current situation } \\
\text { - identification of possible causes }\end{array}$ & $\begin{array}{l}\text { - data collection plan (standardisation) } \\
\text { - Sigma metrics: initial assessment } \\
\text { - prioritisation of causes (Pareto) }\end{array}$ & $\begin{array}{l}\text { - Pareto diagram } \\
\text { - control charts } \\
\text { - process map }\end{array}$ \\
\hline Analyse & $\begin{array}{l}\text { - data-based identification of causes } \\
\text { - identification of relationships among } \\
\text { variables }\end{array}$ & $\begin{array}{l}\text { - brainstorming sessions } \\
\text { - Ishikawa diagram } \\
\text { - analysis of FMEA data }\end{array}$ & $\begin{array}{l}\text { - logical analysis } \\
\text { - hypothesis testing } \\
\text { - brainstorming } \\
\text { - Ishikawa diagram }\end{array}$ \\
\hline Improve & $\begin{array}{l}\text { - prioritisation of causes through FMEA } \\
\text { - definition of improved process } \\
\text { - assurance of implemented actions }\end{array}$ & $\begin{array}{l}\text { - corrective actions plan } \\
\text { - process standardisation }\end{array}$ & - brainstorming \\
\hline Control & $\begin{array}{l}\text { - quantification of project benefits } \\
\text { - project closure communication }\end{array}$ & $\begin{array}{l}\text { - metric assessment of improved process } \\
\text { - monitoring plan of implemented } \\
\text { corrective actions }\end{array}$ & $\begin{array}{l}\text { - control charts } \\
\text { - descriptive statistics }\end{array}$ \\
\hline
\end{tabular}

Source: Thakore et al. (2014) and Garrido-Vega et al. (2016) 


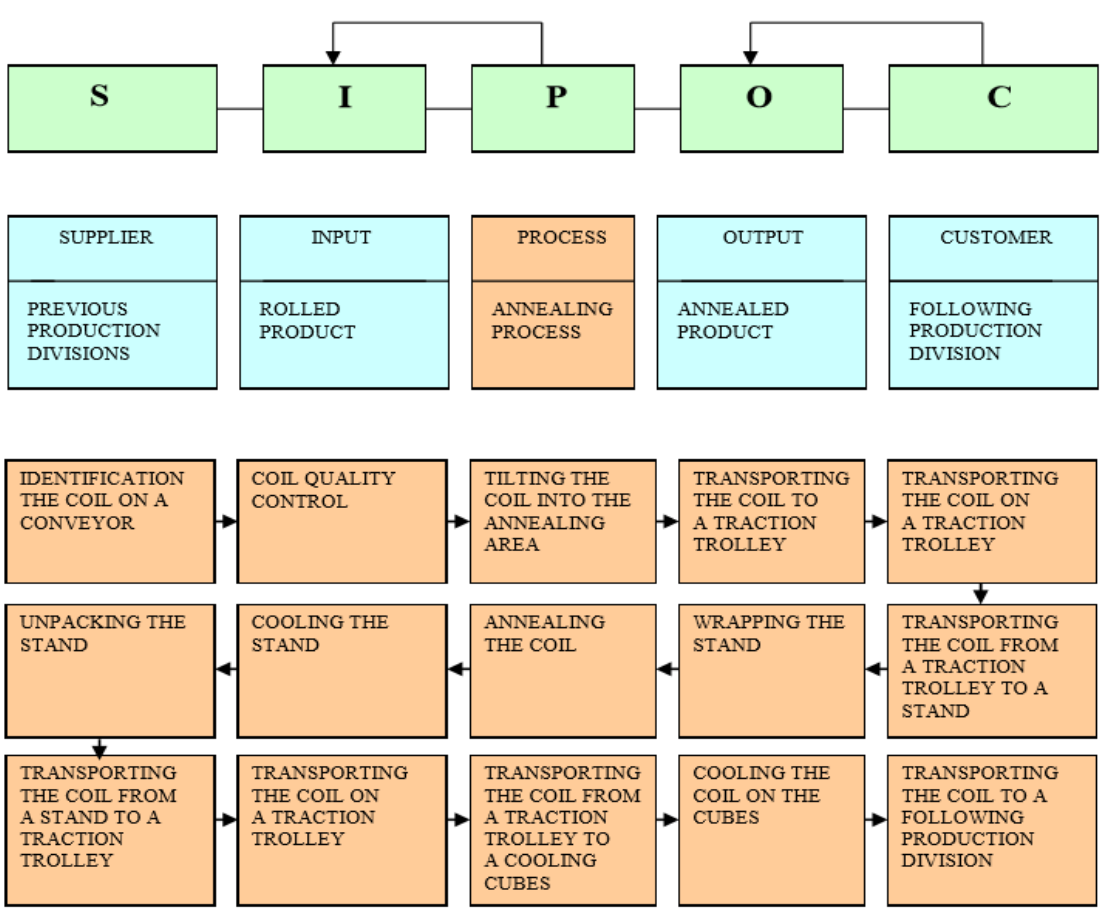

Fig. 1 Supplier-Input-Process-Output-Customer diagram of annealing process

\section{Phase M - Measure}

The measurement process was carried out within one month and was divided into two groups:

1. Measurement of input and delivery process: The measurement was aimed at checking whether the specific input requirements are consistent with the final output product. It was necessary to determine by measuring whether the defect occurred during the process of order receive or during the production process.

2. Measurement of output: The measurement was designed to identify the number of defects for each defect type occurring during the product control process. More than 1,100 of annealed coils were subjected to control. Two basic types of defects were identified by Pareto analysis: mechanical damage and sticking of the coil.

To evaluate the process performance, a measurement based on the number of defects per million opportunities was used. For this case, several criteria can be used to calculate and express the defect rate:

- Defects per million opportunities:

$D P M O=\frac{\text { total number of defects } \times 1,000,000}{\text { no. of units } \times \text { no. of defect opportunities per unit }}=\frac{453 \times 1,000,000}{1,118 \times 5}=81,037.6$

- Sigma level is a metric that measures the process error rate, based on the DPMO estimate: According to conversion table, 81,038 DPMO corresponds to a sigma level of 2.9.

- Proportion defective and Final Yield: Almost $40 \%$ of the products delivered to the customer did not meet the specified requirements, $32 \%$ of which were represented by defects in the mechanical category. The remaining $8 \%$ were included in some other categories (annealing defect, purity, corrosion, graphite).

\section{Phase A - Analyse}

In the Measure phase, two basic types of coil defects of the mechanical category were identified: mechanical damage and sticking. The following tools were used to identify the causes of these defects: brainstorming, Ishikawa diagram, logical analysis. In combination with these methods, the data from FMEA forms were also used to identify the root causes of the issues. FMEA has not been implemented in this improvement project. As the organisation has been active supplier to the automotive industry for a long time, FMEA has already been introduced in organisation.

Analysing the FMEA data, it was found that mechanical damage and sticking occur most frequently during the coil handling process. With regard to the determination of the risk priority number, factors that may cause mechanical damage and sticking of the coil were identified and used to construct the Ishikawa diagram.

The Ishikawa diagram helped to identify the possible factors causing mechanical damage and sticking of the coil during the process of handling: input conveyor, conventional insert (auxiliary material), magnet and traction trolley.

The analysis of FMEA data and the Ishikawa diagram indicate the potential causal relationships between these factors and the examined problem. For the true causality, it was necessary to examine the identified factors by observation and verify the root cause by logical analysis.

1. Input conveyor - the causal relationship of the input conveyor with the coil mechanical damage was revealed by observation. The input conveyor was in an unsatisfactory technical condition. The damage to the rail, on which the individual conveyor sections are moved by the wheel mechanism to tilt the coil into the annealing operation, has been observed. Due to the fact that the rail did not fulfil its function, the conveyor sections fell to the floor level. When the conveyor was moving, there was a friction between the floor and the coil. Therefore, the front part of the coil was mechanically damaged.

2. Conventional insert - conventional insert is an auxiliary material that is used for wrapping the coils to the stand. To avoid their direct contact, it is inserted between the coils. The conventional insert must be clean, free of foreign objects and damage. On conventional inserts, deficiencies in the form of cracks, sharp edges and deformed surfaces occurred. It was confirmed by observation that such conventional inserts caused the mechanical damage to the delivered product. 


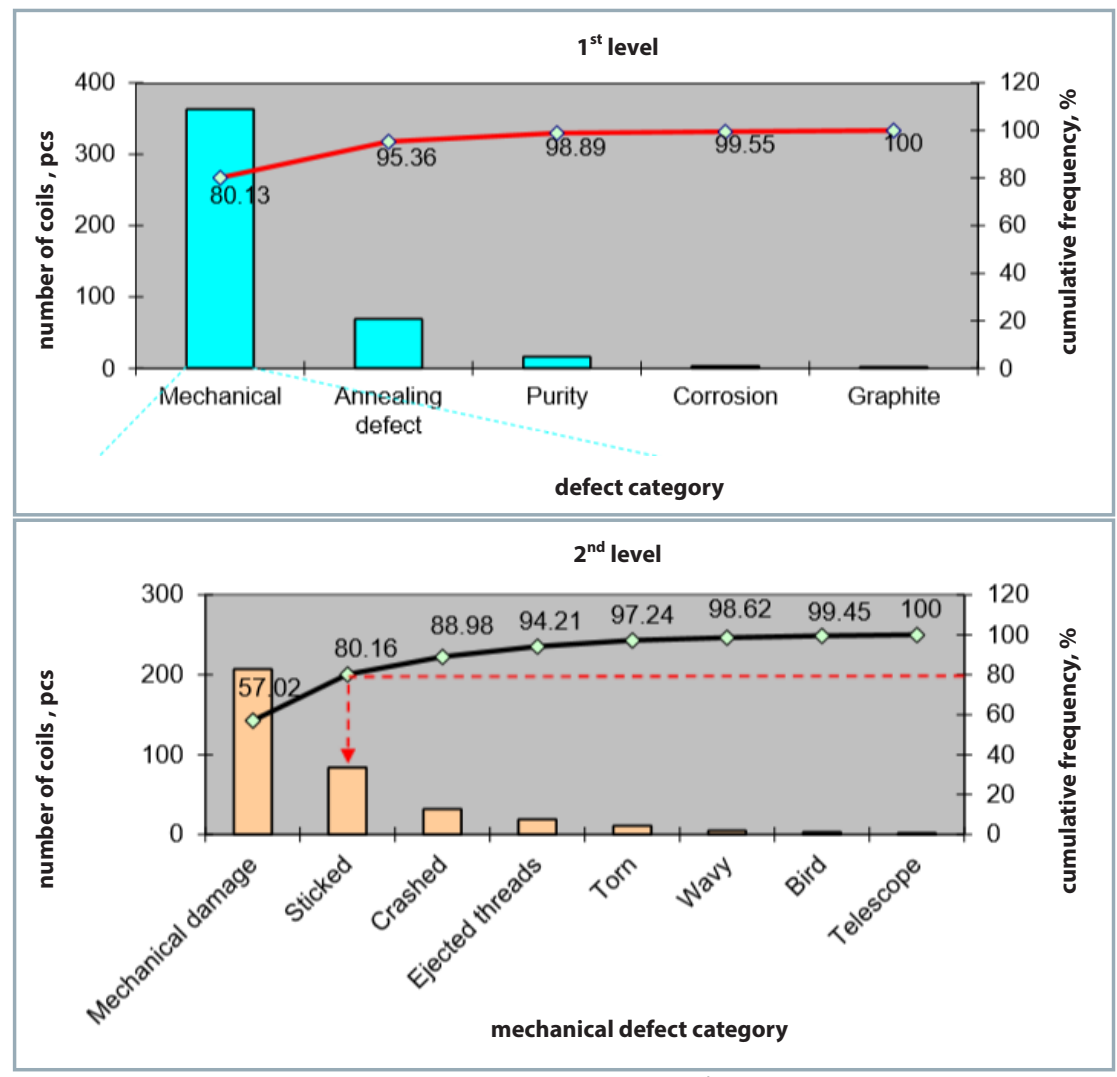

Fig. 2 Pareto diagram of product defects ( $1^{\text {st }}$ and $2^{\text {nd }}$ level)

Conventional inserts inappropriate for the intended purpose were also used in the process.
3. Magnet and traction trolley - the magnet and the traction trolley represent the equipment for transporting the product - the coil to a designated location. The fall from transport equipment was the main cause of the coil mechanical damage. The mechanical damage on a large scale was usually caused by a fall of the coil from the magnet. Therefore, the product had to be scrapped in the majority of cases. Observation has revealed that product is also mechanically damaged when the coils are stored on a traction trolley. The width and height of each coil were not always the same. Therefore, the coils were captured and the threads of the adjacent coils were hit and pushed together.

These factors had significant impact on the resulting product, but the root cause of defects was still unclear. For that, the method of logical cause analysis was used.

There are two types of products entering the operation: the coil of steel sheet and the coil of packaging sheet, which is degreased by continuous annealing by passing through the furnace unit before coming to the processing. In order to be processed in the furnace unit, the coil must be rotated. Then the rotated coil is placed on the input conveyor. Incorrect rotation of the coil could be a root

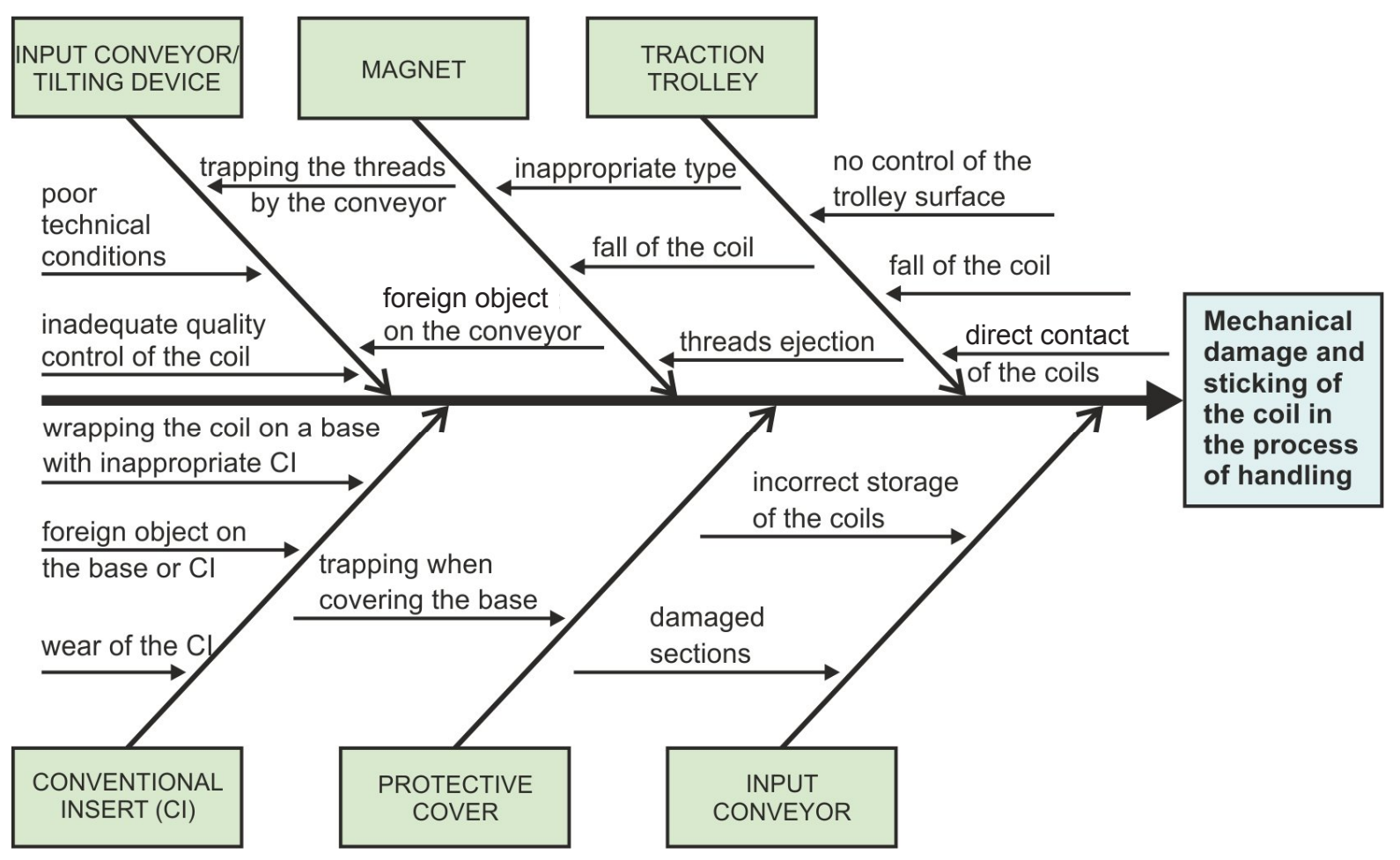

Fig. 3 Ishikawa diagram - mechanical damage and sticking of annealed coil 
cause resulting in mechanical damage of the product. This assumption was verified by a visual control.

The incorrect rotation of the coil was confirmed as the root cause of mechanical damage and sticking of the coil. After tilting, the coil is withdrawn by the magnet and stored on the traction trolley. If the coil is rotated incorrectly on the input conveyor, the threads of the coil are ejected during withdrawal due to magnetisation. When the coil is stored on the traction trolley, the threads remain ejected even after the magnet is turned off. Any further manipulation with the coil results in mechanical damage, either when the coil is wrapped on the base or when the conventional insert is placed between the coils. The pushing and deformation of the ejected threads lead to a sticking of the coils during the annealing process.

\section{Phase I - Improve}

Several process improvements were introduced to the production process:

1. Input conveyor: since the mechanical damage of the coil was caused by the unsatisfactory condition of the input conveyor rail, the non-functional rail was replaced with a functional one.

2. Conventional insert: due to the deficiencies of the conventional insert material in the form of cracks, sharp edges and deformed surfaces, it was suggested to suspend the use of non-conforming conventional inserts (whose crack length and deformation exceed the allowed values). There was a requirement to produce a new conventional insert, taking into account the qualities of the material used for production.

3. Magnet and traction trolley: A new magnet with much higher magnetisation force was purchased for operation. The risk of the coil falling was completely eliminated. It was shown that mechanical damage occurred mostly during the process of the coils storage on a traction trolley. In this case, a more radical solution was proposed in the form of complete suspension of the coil transport on the traction trolley.

4. Human factor - incorrect rotation of the coil: This factor was identified as the root cause of mechanical damage and sticking of coils. Incorrect rotation of the coil was determined as a trigger aspect that had a causal relationship with the activation of the two previous factors. It was proposed to simplify the system for detecting the correctness of the coil storage on the input conveyor, by marking the packaging material with the arrow in the direction of input.

\section{Phase C - Control}

After the implementation of these solutions into operation, the results were tested and measured for one month. Approximately 1,100 pieces of annealed coils were controlled. A significant decrease in mechanical defect category (about 70\%), but also a significant increase of about $47 \%$ in the annealing category have been achieved.

After identifying the true cause of the problem, some improvements occurred almost immediately. The indicators were changed as follows:

- defects per million opportunities: 39,636;
- sigma level: 39,636 DPMO corresponds to a sigma level of 3.3;

- proportion defective and Final Yield: $20 \%$ of the products delivered to the customer do not meet the specified requirements, of which almost $10 \%$ represent defects in the mechanical category. The remaining $10 \%$ are defects in other categories (annealing defect, purity, corrosion, graphite).

The implementation of the proposed improvements has significantly helped to reduce the problem of mechanical damage and sticking of the coil. The defects per million opportunities indicator value has decreased from 81,038 (2.9 Sigma) to 39,636 DPMO (3.3 Sigma). The Sigma level has improved approximately by 0.4 Sigma. The goal of the project - to reduce the number of failed deliveries by $50 \%$ (to less than 20\%) and reduce processing costs by $50 \%$ has been met.

\section{Conclusions}

Using the DMAIC concept of the Six Sigma methodology, the main goal of the project was to improve the quality of the product delivered to the internal customer. The application of the DMAIC tool allowed improving the quality of annealing operation in five important phases. During these phases, the process was defined in detail, the data from the process were gathered, the causes of defects were analysed and the true cause of poor quality of delivered product was revealed. Process improvement measures were proposed and subsequently implemented in operation. Therefore, significant benefits in reduction of the defects of delivered product, as well as the costs of poor quality in the annealing operation have been achieved.

The results achieved by the DMAIC tool of the Six Sigma methodology have confirmed the suitability of its use. The application of DMAIC has successfully solved the problem and modified some processes causing the product defects.

In this paper, it is shown that the DMAIC tool can be applied also within metallurgic operation. Benefits from the DMAIC implementation can be summarised as follows: fulfilling the internal customer's requirement in terms of delivering the product of the required quality to the following production division, reducing and saving of costs associated with the re-adjusting of non-conforming products and benefit in the field of safety and protection of employees. Not only on the qualitative level but also the benefits on the economic and safety level can be achieved.

The case study presents the way in which the Six Sigma and DMAIC implementation can help organisations to improve their processes and thus contribute to their effort to achieve the process and business excellence. It can be used as a guiding reference for managers, project managers and engineers to implement specific improvement projects in manufacturing organisations.

\section{Acknowledgements}

The research published in this paper was developed within the project KEGA 024TUKE-4/2015: New educational methods in the Integrated Management Systems study programme, supported by the Slovak Ministry of Education, Science, Research and Sport. 


\section{References}

BRUE, G. - HOWES, R. 2005. Six Sigma: the MacGraw-Hill 36 hours course. New York: McGraw-Hill Companies Inc., 520 pp. ISBN 9780071446020.

GARRIDO-VEGA, P. - SACRISTÁN-DIÁZ, M. - MAGANA-RAMÍREZ, L. M. 2016. Six Sigma in SMEs with low production volumes. A successful experience in aeronautics. In Universia Business Review, no. 51, pp. 51-71. (In Spanish: Seis Sigma en PYMES con bajo volumen de producción. Una experiencia de éxito en aeronáutica).

GARZA-REYES, J. A. - ORAIFIGE, I. - SORIANO-MEIER, H. HARMANTO, D. - ROCHA-LONA, L. 2010. An empirical application of Six Sigma and DMAIC methodology for business process improvement. In International Conference on Flexible Automation and Intelligent Manufacturing 2010. Oakland, California: FAIM pp. 92-100. ISBN 9781617827143.

GIJO, E. V. - RAO, T. S. 2005. Six Sigma implementation - Hurdles and more hurdles. In Total Quality Management and Business Excellence, vol. 16, no. 6, pp. 721-725.

GIJO, E.V. - SCARIA, J. 2013. Process improvement through Six Sigma with Beta correction: a case study of manufacturing company. In The International Journal of Advanced Manufacturing Technology, vol. 71, no. 1, pp. 717-730.

INGALDI, M. - KOTUS, M. - LESTYÁNSZKA-ŠKŮRKOVÁ, K. 2016. Using $3 \times 3$ matrix to evaluate the manufacturing technology in food company. In Acta Technologica Agriculturae, vol. 19, no. 2, pp. 52-56.

JIRASUKPRASERT, P. - GARZA-REYES, J. A. - KUMAR, V. - LIM, M. K. 2014. A Six Sigma and DMAIC application for the reduction of defects in a rubber gloves manufacturing process. In International Journal of Lean Six Sigma, vol. 5, no. 1, pp. 2-21.

JIRASUKPRASERT, P. - GARZA-REYES, J. A. - SORIANO-MEYER, H. ROCHA-LONA, L. 2012. A case study of defects reduction in a rubber gloves manufacturing process by applying Six Sigma principles and DMAIC problem solving methodology. In International Conference on Industrial Engineering and Operations Management 2012 Istanbul: Industrial Engineering and Operations Management Society, pp. 472-481. ISBN 9780985549701.
OMACHONU, V. K. - ROSS, J. E. 2004. Principles of Total Quality. Florida: CRC Press, 512 pp. ISBN 9781574443264.

PATIL, S. D. - GANGANALLIMATH, M. M. - MATH, R. B. - KARIGAR, Y. 2015. Application of Six Sigma method to reduce defects in green sand casting process: A case study. In International Journal on Recent Technologies in Mechanical and Electrical Engineering, vol. 2, no. 6, pp. 37-42.

PICA, S. 2011. DMAIC and its Contribution to the Area of Process Quality Improvement within the Six Sigma Method. Master Thesis. Košice: Technical University of Košice, 83 pp. (In Slovak: DMAIC a jeho prínos $v$ oblasti zlepšovania kvality procesov $v$ rámci metodiky Six Sigma).

PRÍSTAVKA, M. - KOTOROVÁ, M. - SAVOV, R. 2016. Quality control in production processes. In Acta Technologica Agriculturae, vol. 19, no. 3, pp. 77-83.

PYZDEK, T. - KELLER, P. A. 2010. The Six Sigma Handbook: A complete guide for greenbelts, black belts, and managers at all levels. New York: McGraw-Hill Companies Inc., 548 pp. ISBN 9780071623377.

RUSINKO, L. - HOVANEC, M. 2011. Continuous improvement of quality management system to operate with ergonomics. In International Conference on Quality and Reliability of Technical Systems 2011. Košice: Technical University of Košice, pp. 251-255. ISBN 9788055306124. (In Slovak: Neustále zlepšovanie systému manažérstva kvality $v$ súčinnosti s ergonómiou).

TEPLICKÁ, K. - ČULKOVÁ, K. - ŽELEZNÍK, O. 2015. Application of Bayess principle optimum - optimization model for managerial decision and continual improvement. In Polish Journal of Management Studies, vol. 12, no. 2, pp. 170-178.

THAKORE, R. - DAVE, R. - PARSANA, T. - SOLANKI, A. 2014. A review: Six Sigma implementation practice in manufacturing industries. In International Journal of Engineering Research and Applications, vol. 4, no. 1, pp. 63-69. 